\title{
Retrograde Repression of Growth-Associated Protein-43 mRNA Expression in Rat Cortical Neurons
}

\author{
Soheila Karimi-Abdolrezaee and David J. Schreyer \\ Cameco MS Neuroscience Research Center and Department of Anatomy and Cell Biology, University of Saskatchewan, \\ Saskatoon, Canada S7K OM7
}

\begin{abstract}
Corticospinal neurons support rapid growth of axons toward spinal cord targets in the perinatal period. Initial axon growth is accompanied by elevated expression of growth-associated protein-43 (GAP-43), which then declines in postnatal development. To investigate whether expression of GAP-43 mRNA is regulated by retrograde signals, we injected colchicine into the corticospinal tract to block retrograde axonal transport during a time when GAP-43 is normally declining in corticospinal neurons. Colchicine caused a prolongation of high GAP-43 mRNA expression in neurons located in layer $\mathrm{V}$ (but not other layers) of sensorimotor cortex. We next used osmotic minipumps to infuse soluble adult spinal cord extract into the sensorimotor cortex. This resulted in a premature downregulation of GAP-43 mRNA in identified corticospinal neurons. GAP-43 repressive
\end{abstract}

activity was found in extracts of the spinal cord tissue as young as postnatal day 8 . The effect of spinal cord extract in vivo was not mimicked by adult cerebellar or muscle extracts. Cultures of postnatal cortical neurons also underwent downregulation of GAP-43 mRNA when treated with spinal cord extract. Activation of cAMP signaling also repressed GAP-43 mRNA in cortical cultures, and the repressive effect of spinal cord extract was diminished by an adenyl cyclase inhibitor. Thus, GAP-43 mRNA may be downregulated late in development by a target-derived retrograde repressive factor, and this effect may be mediated by cAMP second messenger signaling.

Key words: GAP-43; corticospinal neuron; spinal cord; development; gene repression; rat; retrograde signal; in situ hybridization
Rat corticospinal tract (CST) neurons located in layer $\mathrm{V}$ of the cerebral cortex (Hicks and D'Amato, 1968) are generated on embryonic days 15-17 (E15-E17) (Berry and Rogers, 1965; Miller, 1987a,b). They migrate to their final position in the cortex shortly thereafter (Berry and Rogers, 1965; Hicks and D'Amato, 1968) and immediately initiate axon growth. CST axons reach the spinomedullary junction at about the day of birth, and by postnatal day 14 (P14) the longest ones reach the sacral segments (Schreyer and Jones, 1982). Terminal arborization within the spinal gray matter begins a few days after the arrival of CST axons at each segment (Schreyer and Jones, 1982), but the stable, adult-like pattern of branching and varicosity formation is not achieved until P28 (S. Karimi-Abdolrezaee, V. Verge, and D. Schreyer, unpublished observations).

GAP-43 is a growth-associated protein that appears to play a role in signal transduction related to growth cone guidance (Skene, 1989; Strittmatter et al., 1992; Benowitz and Routtenberg, 1997). CST neurons express high levels of GAP-43 virtually as soon as they migrate to their final position in the cortex. GAP-43 mRNA expression by CST neurons eventually declines in two distinct phases (Karimi-Abdolrezaee, Verge, and Schreyer, unpublished observations). Between P8 and P12, half of initial GAP-43 mRNA expression is lost. This period corresponds with a period of axon pruning and with initial target contact, and is just before the initiation of myelination. Between P21 and P28 there is another, distinct, twofold decrease in GAP-43 mRNA

\footnotetext{
Received April 26, 2001; revised Oct. 10, 2001; accepted Dec. 18, 2001.

This work was supported by the Medical Research Council of Canada and the Saskatchewan Neurotrauma Initiative.

Correspondence should be addressed to David J. Schreyer, Cameco MS Neuroscience Research Center, Room 5800, Saskatoon City Hospital, 701 Queen Street, Saskatoon, Canada S7K 0M7. E-mail: schreyer@duke.usask.ca.

Copyright (C) 2002 Society for Neuroscience $0270-6474 / 02 / 221816-07 \$ 15.00 / 0$
}

expression, occurring at approximately the time when CST terminal arbors in the spinal cord attain their final form (KarimiAbdolrezaee, Verge, and Schreyer, unpublished observations). The mechanisms that lead to these two distinct declines in GAP-43 mRNA expression during CST neuronal maturation are not completely understood.

Previous studies have reported a correlation between target contact and downregulation of GAP-43 expression in rat dorsal root ganglion (DRG) neurons (Baizer and Fishman, 1987; Bisby, 1988; Schreyer and Skene, 1991). Moreover, application of colchicine to interrupt axonal transport results in GAP-43 upregulation in adult DRG neurons (Woolf et al., 1990). In retinal ganglion neurons of zebrafish, GAP-43 is re-expressed after injury, and then downregulated after these neurons recontact the optic tectum (Bormann et al., 1998). Evidence has been presented that target-derived factors act to downregulate GAP-43 expression late in the development of spinal motoneurons (Caroni and Becker, 1992). These findings suggest that target-derived signals may play a role in suppressing GAP-43 expression at the close of development, or after regenerative target reinnervation in the adult.

In the present study, we examine the hypothesis that developmental downregulation of GAP-43 in CST neurons in vivo is regulated by retrograde signals from target tissue. We also examine the effect of target-derived factors in cultures of postnatal cerebral cortex. Our findings indicate that developmental downregulation of GAP-43 mRNA is mediated by retrograde signals and can be induced prematurely by exposure of CST neurons to spinal cord target tissue extract.

Previous studies of cultured DRG neurons and RN46A cells (Schreyer et al., 1997; Andersen et al., 2000a,b) have shown that activation of cAMP signaling reduces GAP-43 expression. To test 
whether cAMP may be involved in mediating GAP-43 repressive activity of extracellular origin, we examine the role of cAMP in postnatal cortical cultures. We find that cAMP may mediate the action of an extracellular signal that represses GAP-43 mRNA expression in postnatal cortical neurons.

\section{MATERIALS AND METHODS}

Wistar rats were bred in our laboratories, in accordance with the standards of the Canadian Council on Animal Care. All procedures using animals were approved beforehand by a local animal care committee. Reagents were obtained from Sigma-Aldrich Canada (Oakville, Ontario, Canada) unless otherwise noted. Procedures were performed at room temperature unless otherwise noted.

Retrograde labeling of corticospinal neurons. To distinguish CST neurons from other pyramidal-shaped neurons within the cerebral cortex, Wistar rats were anesthetized using halothane and retrogradely labeled by unilateral injection of Fast Blue (FB) (3\% suspension in water) into the left CST at cervical level C2 or C3. The animals survived for 5-7 d, and were then perfused transcardially with cold $10 \mathrm{~mm}$ PBS followed by cold $4 \%$ paraformaldehyde (PF) in $0.1 \mathrm{M}$ phosphate buffer (PB). The dissected brains were post-fixed in $10 \%$ sucrose and $4 \%$ PF in $0.1 \mathrm{M} \mathrm{PB}$ on ice (overnight) and cryoprotected in a $20 \%$ sucrose solution in PBS at $4{ }^{\circ} \mathrm{C}$ for $24 \mathrm{hr}$. Brains were embedded in OCT compound (Sakura Finetech, La Jolla, CA) and frozen on dry ice. Cryostat sections were cut at $6 \mu \mathrm{m}$ and thawed onto ProbeOn (FisherBiotech, Edmonton, Alberta, Canada) slides and stored at $-20^{\circ} \mathrm{C}$ until use for in situ hybridization (see below).

Application of colchicine to the spinal cord. To block axonal transport in CST axons, colchicine was injected into the spinal cord. Rats aged P23 or P24 were divided into two groups. Under halothane anesthesia, one group of normal rats received a vehicle only injection of $0.5 \mu \mathrm{l}$ of PBS, whereas the other group received an injection of $0.5 \mu \mathrm{l}$ of vehicle containing $4 \mu \mathrm{g} / \mu \mathrm{l}$ of colchicine. The spinal cord was exposed, and colchicine or PBS was injected into the left dorsal funiculus at cervical level $\mathrm{C} 2$ or $\mathrm{C} 3$ using a Hamilton syringe. To verify the effectiveness of colchicine in blocking axonal transport, $1 \mu \mathrm{l}$ of $3 \% \mathrm{FB}$ was also injected in the same rats, one segment distal to the injection site for colchicine or PBS. The injections were performed slowly $(0.1 \mu \mathrm{l}$ per min), and the glass micropipette was left in place for an additional 5 min to avoid excessive leakage of the dye onto the spinal cord surface. On P28, the animals were perfused, fixed, and sectioned as described above. Only slides from those colchicine-injected animals that showed no FB labeling of cortical neurons were used in further analysis. PBS-injected animals usually showed good FB labeling of CST neurons.

Tissue extract preparation. Tissue extracts were prepared according to the method of Houenou et al. (1991) with some modifications. All steps were performed at $0-3^{\circ} \mathrm{C}$ under sterile conditions. After killing by exposure to a carbon dioxide atmosphere, spinal cord, cerebellum, or hindlimb skeletal muscle were removed from one adult rat, or spinal cords were removed and pooled from an entire litter (12-16) of P8, P14, or P21 rat pups. Spinal cord and cerebellar tissues were placed in HBSS, and all nerve roots and meninges were removed. All tissues were subsequently frozen using liquid nitrogen.

To prepare extracts, tissue was weighed and homogenized in five volumes of $0.9 \%$ sodium chloride and $1 \mathrm{~mm}$ phenylmethelsulfonylfluoride (PMSF). Homogenization was performed using a Teflon plunger with glass pestle attached to a power drill on maximum speed for $2 \mathrm{~min}$ with $30 \mathrm{sec}$ cooling breaks every $20 \mathrm{sec}$. The homogenized tissue was centrifuged at $200 \times g$ for $15 \mathrm{~min}$ to remove large cell debris. The low-speed supernatant was collected and centrifuged at $23,000 \times g$ in a fixed angle rotor for $1 \mathrm{hr}$. The high-speed supernatant was collected as a crude soluble extract, then stored at $-70^{\circ} \mathrm{C}$. Protein concentration was assayed using a BCA protein assay kit (Bio-Rad, Mississauga, Ontario, Canada).

Implantation of osmotic minipumps. We used Alzet (Durect, Cupertino, CA) osmotic minipumps (model 1007D; $7 \mathrm{~d}, 0.5 \mu \mathrm{l} / \mathrm{hr}$ ) to deliver tissue extracts into the sensorimotor cortex. A cannula was fashioned from a cut length of 27 gauge needle that was bent at a right angle and attached to the pump using SILASTIC tubing. The day before implantation, osmotic minipumps and their attachments were filled with either tissue extracts [2 $\mathrm{mg}$ of protein per milliliter in $0.9 \%$ sodium chloride, saline alone, or saline plus $2 \mathrm{mg} / \mathrm{ml}$ bovine serum albumin (BSA)] under sterile conditions, and incubated overnight at $37^{\circ} \mathrm{C}$. Rats aged $\mathrm{P} 13$ were anesthetized using halothane, the skull was exposed, and a hole was made on the right side $1 \mathrm{~mm}$ posterior to the coronal suture and $2 \mathrm{~mm}$ lateral to the sagittal suture. The cannula was inserted through the opening until the tip was $\sim 1 \mathrm{~mm}$ below the surface of the cerebral cortex and secured to the skull using cyanoacrylate glue. These animals were also injected with $1 \mu \mathrm{l}$ of $3 \% \mathrm{FB}$ at the left cervical spinal cord (as above), to identify CST neurons in the right cortex. On P18, under halothane anesthesia, the animals were perfused, fixed and sectioned as described above.

The density of FB-labeled CST neurons in pump-implanted animals was similar to the density obtained when no pumps were present. There was no consistent difference in FB labeling density between control and extract-treated animals. Cannula placement sites were typically characterized by a radially oriented cyst surrounded by a 50-100 $\mu \mathrm{m}$ zone of disorganized scar tissue. FB-labeled cells sampled for analysis were located outside the zone of obvious damage, but within $2 \mathrm{~mm}$ of the site of cannula placement.

In situ hybridization of tissue sections. A radioactive in situ hybridization procedure was performed using cryostat sections taken from colchicinetreated and tissue extract-treated animals and their controls. Pretreatment of tissue sections was performed in accordance to the technique of Giehl and Tetzlaff (1996). The frozen tissue sections were warmed for 20 min and then treated in 4\% PF in PBS for 20 min, followed by washes $(3 \times 5 \mathrm{~min})$ in PBS. The sections were treated with $20 \mu \mathrm{g} / \mathrm{ml}$ proteinase $\mathrm{K}$ in $50 \mathrm{~mm}$ Tris-HCl, pH 7.6, and $0.5 \mathrm{~mm}$ EDTA for $6 \mathrm{~min}$, then washed with PBS once for $5 \mathrm{~min}$. The sections were fixed in $4 \% \mathrm{PF}$ in PBS for 5 min, followed by washing with PBS $(2 \times 5 \mathrm{~min})$, and then rinsed with DEPC-treated water for another $5 \mathrm{~min}$. The sections were dehydrated using 70\% (1 min), 90\% (1 min), and 100\% (30 sec) ethanol, then air-dried.

An oligonucleotide probe for GAP-43 mRNA was synthesized complementary to bases $220-270$ of the rat GAP-43 coding sequence (Basi et al., 1987). The probe was end-labeled with ${ }^{35}$ S-ATP using deoxynucleotide terminal transferase. Hybridization was performed based on the method of Verge et al. (1992). The pretreated slides were hybridized for $16-18 \mathrm{hr}$ at $42^{\circ} \mathrm{C}$ with $10^{7} \mathrm{cpm}$ of labeled probe per $1 \mathrm{ml}$ of a hybridization mixture containing deionized formamide, $20 \times$ SSC, $1 \times$ Denhardt's solution, $20 \%$ sarcosyl ( $N$-lauryl sarcosine), dextran sulfate, and $0.2 \mathrm{M}$ sodium phosphate. After hybridization, sections were rinsed repeatedly $(4 \times 15 \mathrm{~min})$ in $1 \times \mathrm{SSC}$ followed by a final wash starting at $55^{\circ} \mathrm{C}$ and slowly cooled to room temperature. The sections were quickly dipped in distilled water, dehydrated through $60 \%$ and $95 \%$ ethanol (30 sec each), air-dried, and dipped in NTB2 nuclear track emulsion (Eastman Kodak, Rochester, NY) and exposed for $7 \mathrm{~d}$ at $4^{\circ} \mathrm{C}$. After $7 \mathrm{~d}$, the emulsion-coated slides were developed in D19 (Eastman Kodak) for 3 min and fixed in undiluted Rapid Fix (Kodak) for 5 min.

Control hybridization solutions that included no labeled probe, or labeled GAP- 43 probe and $1000 \times$ excess unlabeled GAP- 43 probe, produced no hybridization signal above background. Hybridization with labeled GAP-43 probe was not diminished by inclusion of $1000 \times$ excess unlabeled oligonucleotide complimentary for either c-Jun or T $\alpha 1$-tubulin mRNA.

Postnatal cortical culture. P8 rats were killed in a carbon dioxide atmosphere and cleaned with $70 \%$ ethanol. The brains were dissected, placed in Puck's BSS, and cleaned of all meninges. Cerebral cortices were isolated and minced in fresh Puck's BSS. The tissue was incubated in an enzyme solution containing $20 \mathrm{~mm}$ glucose, $2 \mathrm{~mm}$ pyruvate, 0.2 $\mathrm{mg} / \mathrm{ml} \mathrm{BSA}, 1 \mathrm{~mm}$ mercaptoethanol, $0.02 \%$ DNase, and $20 \mathrm{U} / \mathrm{ml}$ papain in Puck's BSS at $37^{\circ} \mathrm{C}$ for $1.5-2 \mathrm{hr}$. After incubation, the tissues were rinsed briefly with warm Puck's BSS and then placed in a solution containing $2 \mathrm{~mm}$ pyruvate, $0.02 \%$ DNase, $0.5 \mathrm{~mm}$ EDTA, and $0.2 \mathrm{mg} / \mathrm{ml}$ BSA in Puck's BSS. The tissue was gently triturated using a $5 \mathrm{ml}$ plastic pipette until a homogenous suspension was obtained. The cell suspension was centrifuged at $150 \times g$ for $10 \mathrm{~min}$. The cell pellet was resuspended into growth medium containing DMEM (Invitrogen, Toronto, Ontario, Canada) with $0.5 \mathrm{~mm}$ glutamate, $20 \mathrm{~mm}$ glucose, $15 \mathrm{~mm}$ sodium bicarbonate, and $5 \%$ horse serum. Cell density and viability were determined using a hemacytometer and nigrosin exclusion. Cultures were seeded at a density of $1 \times 10^{6}$ cells per $35 \mathrm{~mm}$ culture dish, previously coated with a $0.1 \mathrm{mg} / \mathrm{ml}$ solution of poly-D-lysine at $37^{\circ} \mathrm{C}$ overnight. The cultures were maintained at $37^{\circ} \mathrm{C}$ in a humidified atmosphere of $5 \% \mathrm{CO}_{2}$. On the second day after culture, $20 \mu \mathrm{M}$ cytosine arabinoside was added to the cultures to control proliferation of non-neuronal cells, and $24 \mathrm{hr}$ later the medium was replaced. The cultures were subsequently fed every $2 \mathrm{~d}$. All experimental additives were included in the medium continuously, beginning with initial plating.

Sister cultures not used for in situ hybridization were fixed in $4 \% \mathrm{PF}$ after $5 \mathrm{~d}$ in culture and characterized by immunocytochemistry using monoclonal antibody 9-1E12 against GAP-43 protein (Schreyer and 
Skene, 1991), or monoclonal antibody SDL.3D10 (Sigma Aldrich T8660) against $\beta$-tubulin III, and compared with cresyl violet-stained cultures. Neurons and non-neuronal cells were present, but the characteristic appearance of neuronal cells was easily recognized in cresyl violetstained cultures (data not shown).

In situ hybridization of tissue cultures. In situ hybridization of cultured neurons was performed in accordance with the method of Yamawaki et al. (1993). After 5 d, postnatal cortical cultures were rinsed in warm HBSS, then fixed with $4 \%$ PF in PBS for $30 \mathrm{~min}$. The fixed cultures were washed with PBS $(3 \times 10 \mathrm{~min})$. Cultures were deproteinated in $0.1 \%$ saponin plus $1 \mathrm{~mm}$ EGTA for $30 \mathrm{~min}$, then post-fixed with 4\% PF in PBS for $10 \mathrm{~min}$. The cultures were washed with $0.2 \%$ glycine in PBS $(2 \times 10$ $\mathrm{min})$, then rinsed in PBS $(2 \times 5 \mathrm{~min})$, and washed with DEPC-treated water for $5 \mathrm{~min}$. Cultures were acetylated by treating with $0.1 \mathrm{M}$ triethanolamine and $0.25 \%$ acetic anhydride in DEPC-treated water, $\mathrm{pH}$ 8.0. Then, cultures were rinsed in DEPC-treated water $(2 \times 5 \mathrm{~min})$, and dehydrated through $60,75,85,95$, and $100 \%$ ethanol for 1 min each, and air-dried.

The cultures were hybridized with a hybridization mixture, including $10^{7} \mathrm{cpm}$ of ${ }^{35} \mathrm{~S}$-labeled GAP-43 probe (described above), at $43^{\circ} \mathrm{C}$ for 16-18 hr. Posthybridization washes in $1 \times$ SSC $(4 \times 15 \mathrm{~min})$ were performed at $55^{\circ} \mathrm{C}$, then cultures were dehydrated through $60,75,85,95$, and $100 \%$ ethanol for $1 \mathrm{~min}$ each, and air-dried. The cultures were coated with NTB2 nuclear track emulsion diluted $1: 1$ in water at $4^{\circ} \mathrm{C}$ for $7 \mathrm{~d}$, then developed using Kodak D-19 developer at $19^{\circ} \mathrm{C}$ for $3 \mathrm{~min}$, rinsed in water, fixed in Rapid Fix for $5 \mathrm{~min}$, and rinsed again in running water at $20^{\circ} \mathrm{C}$ for $30 \mathrm{~min}$.

Quantification of in situ hybridization. A Zeiss Axioskope microscope set with dark field optics was used to assess the pattern of cell labeling with the GAP-43 probe. In some experiments, visualization of silver grains with bright field illumination was combined with fluorescence microscopy to reveal GAP-43 mRNA levels in Fast Blue-labeled CST neurons. Electronic images were captured using a Sony 3 CCD video camera and Northern Eclipse imaging software (Empix Imaging, Inc., Mississaugua, Ontario, Canada). Then, Adobe Photoshop software (Adobe Systems Inc., San Jose, CA) was used to combine two images from each field, corresponding to the two visualization techniques.

To quantify GAP-43 mRNA when CST neurons could not be identified using FB (e.g., colchicine injections, tissue culture), the slides or culture dishes were stained with cresyl violet after in situ hybridization. Images were captured using bright-field optics, and a Northern Eclipse subroutine was used to quantify silver grain density over selected neurons. All silver grain density measurements were corrected for grain overlap and background grain density. GAP-43 mRNA hybridization signal was measured for 70-200 neurons taken from two or three slides per animal for the in vivo analysis. For culture experiments, all neurons located within the central $22 \mathrm{~mm}^{2}$ of each of three dishes per experimental condition were analyzed.

\section{RESULTS}

\section{Colchicine blocks downregulation of GAP-43 mRNA}

To investigate whether retrograde signals conveyed from target tissues are involved in developmental downregulation of GAP-43 mRNA in corticospinal neurons, we injected colchicine into the CST at the cervical spinal level on P23 or P24 to disrupt microtubules and block retrograde axonal transport. Virtually no CST neurons could be labeled when FB was injected distal to the colchicine injection site ( $n=5$ animals), compared with extensive labeling of CST neurons in vehicle-injected animals $(n=5$ animals), indicating that retrograde transport was completely blocked by colchicine.

We used in situ hybridization to measure relative GAP-43 mRNA levels in cortical neurons at P28, a time when the GAP-43 content of cortical neurons in general, and CST neurons in particular, would normally have declined to adult levels (KarimiAbdolrezaee, Verge, and Schreyer, unpublished observations). Because we were not able to identify CST neurons by FB labeling in these experiments, we examined GAP-43 mRNA content of neurons in identified cortical layers (Fig. $1 A$ ). We found that colchicine treatment resulted in GAP-43 mRNA levels that were higher than control by $40-50 \%$ in cortical layer $\mathrm{V}$, the location of CST neurons. However, there were no significant effects on the other cortical layers (Fig. $1 B-D$ ). The experimentally induced failure of GAP-43 mRNA to undergo a normal developmental decline was therefore restricted to only the cortical layer that projects axons to the spinal cord.

\section{Spinal cord extract causes a decrease in GAP-43 mRNA in CST neurons}

To determine whether a retrograde signal involved in developmental downregulation of GAP-43 mRNA is derived from target tissue, we examined the effects of spinal cord tissue extract on GAP-43 expression in identified CST neurons. Osmotic minipumps ( $n=7$ animals) were used to infuse spinal cord extracts $(2 \mu \mathrm{g} / \mu \mathrm{l}$ protein) in the vicinity of CST neurons beginning at P13, and they were marked for identification using FB retrograde labeling. Controls ( $n=7$ animals) received infusions of either saline or saline plus $2 \mu \mathrm{g} / \mu \mathrm{l} \mathrm{BSA}$.

We examined CST neurons within $2 \mathrm{~mm}$ of the infusion site, and outside the very narrow zone of tissue damage caused by the infusion cannula (Fig. 2A,B). When we measured relative GAP-43 mRNA hybridization signal at P18, a time before CST neurons normally undergo a final decline in GAP-43 expression (Karimi-Abdolrezaee, Verge, and Schreyer, unpublished observations), we found that infusion of spinal cord extract resulted in a premature downregulation of GAP-43 mRNA levels, by $40-$ $50 \%$ compared with control saline or saline plus BSA-infused animals (Fig. $2 C$ ). To determine whether immature spinal cord tissue expresses a GAP-43 repressive factor similar to that seen in adult extracts, we made extracts from P8, P14, or P21 rat spinal cord $(2 \mu \mathrm{g} / \mu \mathrm{l}$ protein) and infused them into an additional group of P13 rats ( $n=12$ animals). When examined at P18, each of these extracts also caused a reduction of GAP-43 mRNA expression in CST neurons. These reductions were of a magnitude similar to that seen with adult spinal cord extract (Fig. 3). We also implanted some pumps ( $n=6$ animals) containing soluble extracts from adult cerebellum or skeletal muscle $(2 \mu \mathrm{g} / \mu \mathrm{l}$ protein $)$. In situ hybridization revealed that GAP-43 mRNA remained unchanged after treatment with these control extracts (Fig. 3), suggesting that the spinal cord tissue produces GAP-43 repressive factors that are not present in cerebellar or muscle tissue.

\section{Spinal cord extract causes a decrease in GAP-43 mRNA in cortical cultures}

We used in situ hybridization to study the effects of spinal cord extracts on GAP-43 mRNA expression in postnatal cortical cultures. Cultures prepared from P8 or P9 cerebral cortex and maintained in vitro for 5-6 d were composed of neurons that expressed GAP-43 and $\beta$-tubulin III, and non-neuronal cells, which did not express these markers and were not further characterized (see below). We found that chronic exposure to spinal cord extract (final concentration, $100 \mu \mathrm{g} / \mathrm{ml}$ ) resulted in an $\sim 50 \%$ downregulation of GAP-43 mRNA in comparison to control cultures ( $n=7$ experiments) (Fig. 4). Postnatal cortical cultures chronically exposed to extracts from P8, P14, or P21 spinal cord tissue (final concentration, $100 \mu \mathrm{g} / \mathrm{ml}$ ) also showed a similar reduction in GAP-43 mRNA ( $n=3$ experiments) (Fig. 4). Extracts of cerebellum (final concentration, $100 \mu \mathrm{g} / \mathrm{ml}$ ), a tissue that is not normally innervated by cortical neurons, caused a smaller, but significant reduction of GAP-43 mRNA expression in cortical cultures, in contrast to its lack of effect when infused in vivo. 


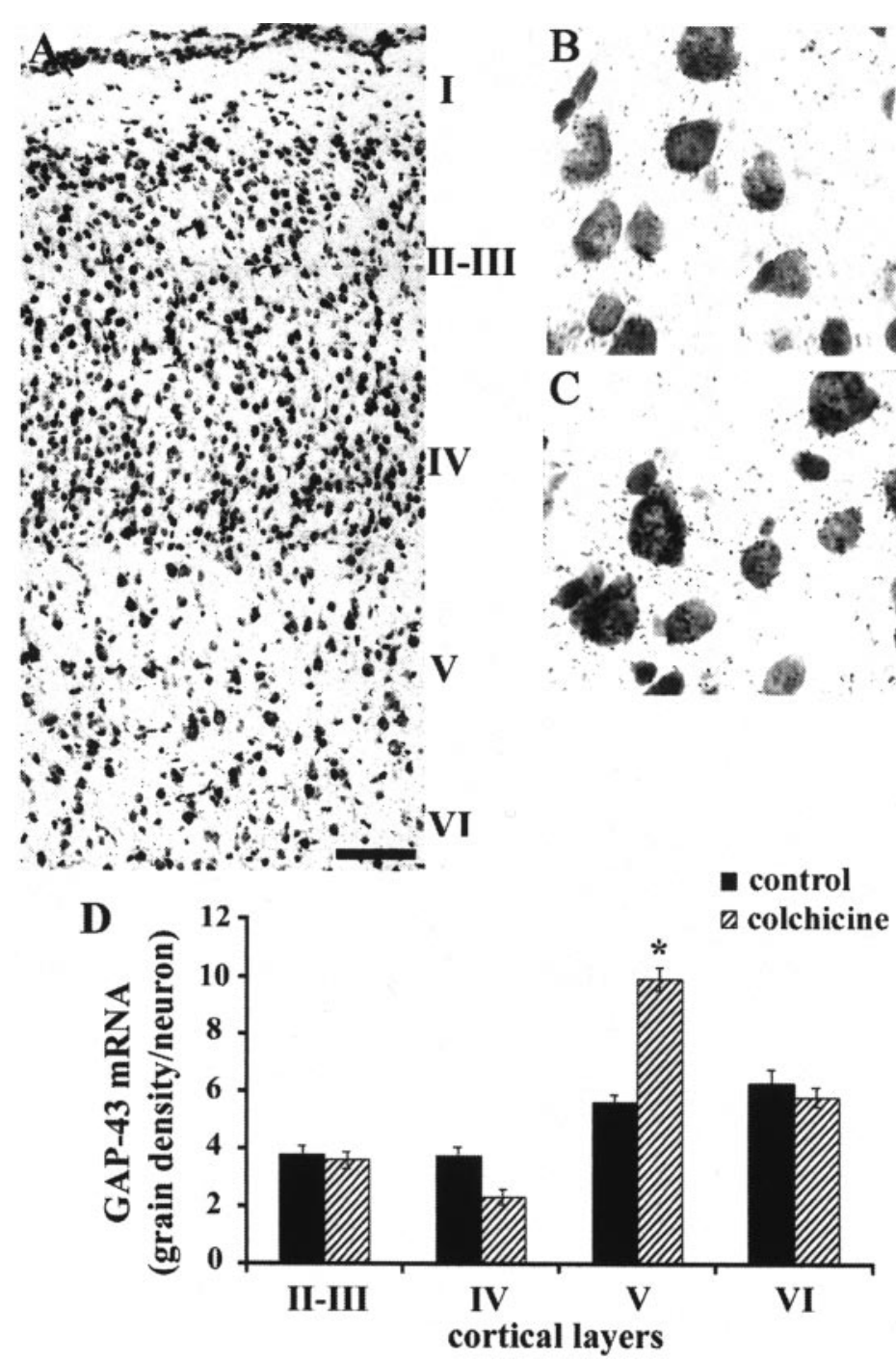

\section{cAMP causes a decrease in GAP-43 mRNA in cortical cultures}

We have previously found that cAMP signaling can downregulate GAP-43 protein expression in cultures of adult DRG neurons (Andersen et al., 2000a) and in the RN46A cell line (Andersen et al., 2000b). Accordingly, we used in situ hybridization to measure relative GAP-43 mRNA expression in cultures of postnatal cortical neurons 5-6 d after chronic exposure to dibutyryl cAMP (dBcAMP), a membrane-permeable analog of cAMP. In cultures exposed to 0.5 or $1.0 \mathrm{~mm} \mathrm{dBcAMP}$ ( $n=6$ experiments), GAP-43 mRNA expression was decreased by $40-60 \%$ compared with control cultures (Fig. 5). To investigate whether the repression of GAP-43 mRNA expression by spinal cord extract was mediated by cAMP signaling, we examined the effect of SQ22,536 (Research Biochemicals, Natick, MA), an adenyl cyclase inhibitor. P8 cortical cultures were chronically treated with adult spinal cord extract with or without the presence of $0.2 \mathrm{~mm} \mathrm{SQ22,536.} \mathrm{This}$ inhibitor blocked $\sim 50 \%$ of GAP-43 repression induced by spinal cord extract compared with control cultures and $>80 \%$ compared with SQ22,536 alone (Fig. 5). The GAP-43 repressive activity of spinal cord may only be partly mediated by the adenyl cyclase pathway or the concentration of SQ22,536 used here may have been too low to block all adenyl cyclase signaling. However, we found that an SQ22,536 concentration of $>0.2 \mathrm{mM}$ was toxic, as
Figure 1. Blocking axonal transport prevents developmental downregulation of GAP-43 in layer V cortical neurons. $A$, Sensorimotor region of cerebral cortex at P28 stained with cresyl violet and showing cortical layers. Scale bar, $150 \mu \mathrm{m} . B, C$, In situ hybridization for GAP-43 in layer $\mathrm{V}$ neurons at $\mathrm{P} 28$. Animal was injected with vehicle alone $(B)$ or colchicine $(C)$ at P23. Scale bar (in $C$ ), $25 \mu \mathrm{m}$. D, Quantification of GAP-43 mRNA in situ hybridization signal in neurons of different cortical layers on P28. Error bars indicate SEM. Colchicine injection resulted in significantly higher expression of GAP-43 mRNA in layer V neurons $\left({ }^{*} p<0.0001\right.$; Student's $t$ test), but not in other layers ( $p>0.05$; Student's $t$ test).

evidenced by a reduction in neuronal survival in P8 cortical cultures (data not shown).

\section{DISCUSSION}

High expression of GAP-43 has been demonstrated throughout the period of axon growth in many developing (Jacobson et al., 1986; Kalil and Skene, 1986; Dani et al., 1991; Fitzgerald et al., 1991; Caroni and Becker, 1992) and successfully regenerating (Skene and Willard, 1981; Benowitz and Lewis, 1983; Bisby, 1988; Woolf et al., 1990; Campbell et al., 1991; Schreyer and Skene, 1991; Bormann et al., 1998) neurons. However, little is known about the mechanisms that cause high GAP-43 expression early in development, the mechanisms that can trigger an increase in GAP-43 expression after adult injury, or the mechanisms that cause a decline in GAP-43 expression at the close of development or after successful regenerative growth. This study examines the hypothesis that neurons express high levels of GAP-43 by default, but that GAP-43 expression is subject to a repressive retrograde signal imparted by target tissues to the axons that innervate them.

\section{Changes in GAP-43 expression during development of the CST}

The growth of CST axons through the rat spinal cord during the first two postnatal weeks (Donatelle, 1977; Schreyer and Jones, 

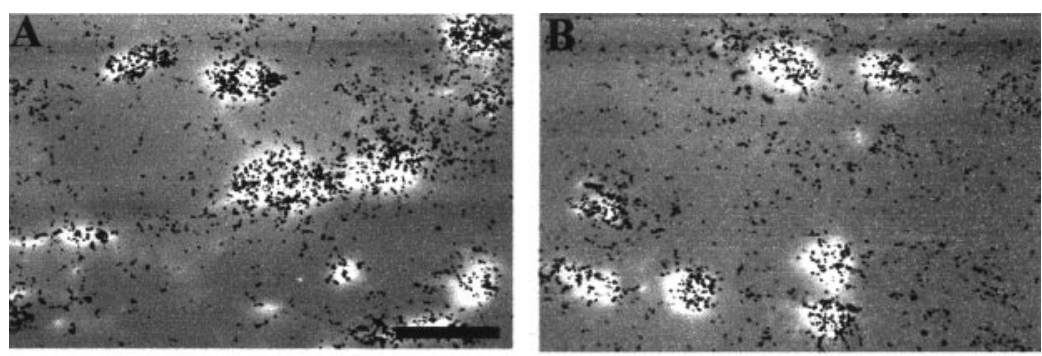

Figure 2. Infusion of extract from adult spinal cord represses GAP-43 mRNA in CST neurons. $A, B$, Electronically combined images of FB-labeled CST neurons and silver grains from in situ hybridization after chronic infusion of saline $(A)$ or adult spinal cord extract $(B)$. Scale bar (in $B$ ), $50 \mu \mathrm{m}$. Quantitative in situ hybridization signal for GAP-43 mRNA in CST neurons identified by FB retrograde labeling at $\mathrm{P} 18(C)$ showed that there was a significant reduction of GAP-43 mRNA after infusion of adult spinal cord extract compared with infusion of saline or saline plus BSA ( ${ }^{*} p<0.001$; one-way ANOVA followed by Tukey's test). Error bars indicate SEM.

C
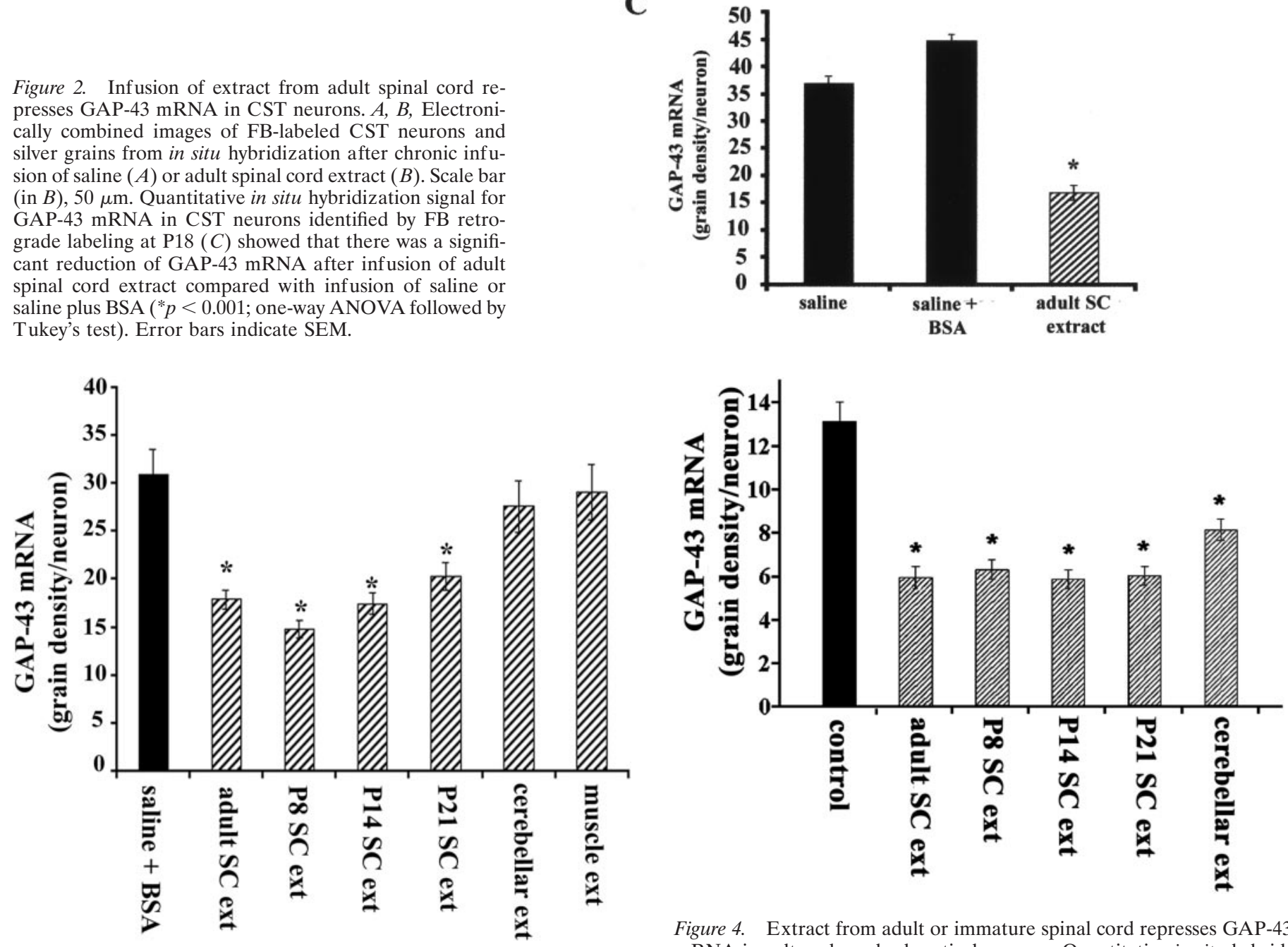

Figure 3. Infusion of extract from immature spinal cord represses GAP-43 mRNA in CST neurons. Quantitative in situ hybridization for GAP-43 in CST neurons identified by Fast Blue retrograde labeling at P18 showed that chronic infusion of soluble extracts from adult, P8, P14, and P21 spinal cord tissue caused similar significant reductions in GAP-43 mRNA compared with infusion of saline plus BSA $\left({ }^{*} p<0.001\right.$; one-way ANOVA followed by Tukey's test). There was no significant difference between the effects of adult, P8, P14, and P21 spinal cord extracts $(p>$ 0.05; ANOVA). Infusion of extracts from adult cerebellum or skeletal muscle caused no change in GAP-43 mRNA levels in CST neurons $(p>$ 0.05; ANOVA). Error bars indicate SEM.

1982; Gribnau et al., 1986) includes several landmarks of maturation. Between P8 and P12 there is a substantial loss of axon numbers (Stanfield and O'Leary, 1985; Schreyer and Jones, 1988; Oudega et al., 1994). This occurs at about the same time that most axons cease growing caudally in the white matter (Schreyer and

Figure 4. Extract from adult or immature spinal cord represses GAP-43 mRNA in cultured cerebral cortical neurons. Quantitative in situ hybridization for GAP-43 in cultures prepared from P8 cortex revealed that exposure to extracts from adult, P8, P14, and P21 spinal cord tissue caused significant reductions in GAP-43 mRNA compared with control after $5 \mathrm{~d}$ in culture ( ${ }^{*} p<0.001$; one-way ANOVA followed by Tukey's test). The effect caused by extract from adult cerebellum was significantly different from both control and adult spinal cord extract $\left({ }^{*} p<0.001\right.$ for both comparisons; Tukey's test). There was no significant difference among the effects of adult and postnatal spinal cord extracts on GAP-43 expression $(p>0.05$; one-way ANOVA). Error bars indicate SEM.

Jones, 1982; Gribnau et al., 1986) and begin making extensive contact with target gray matter (Schreyer and Jones, 1982; Gribnau et al., 1986). Myelination of the first few CST axons in the dorsal columns occurs at $\sim$ P12, but proceeds slowly to reach an adult pattern by $\sim$ P21 (Schreyer and Jones, 1982; KarimiAbdolrezaee, Verge, and Schreyer, unpublished observations). CST axon terminal arbors are initially smooth, straight, and 


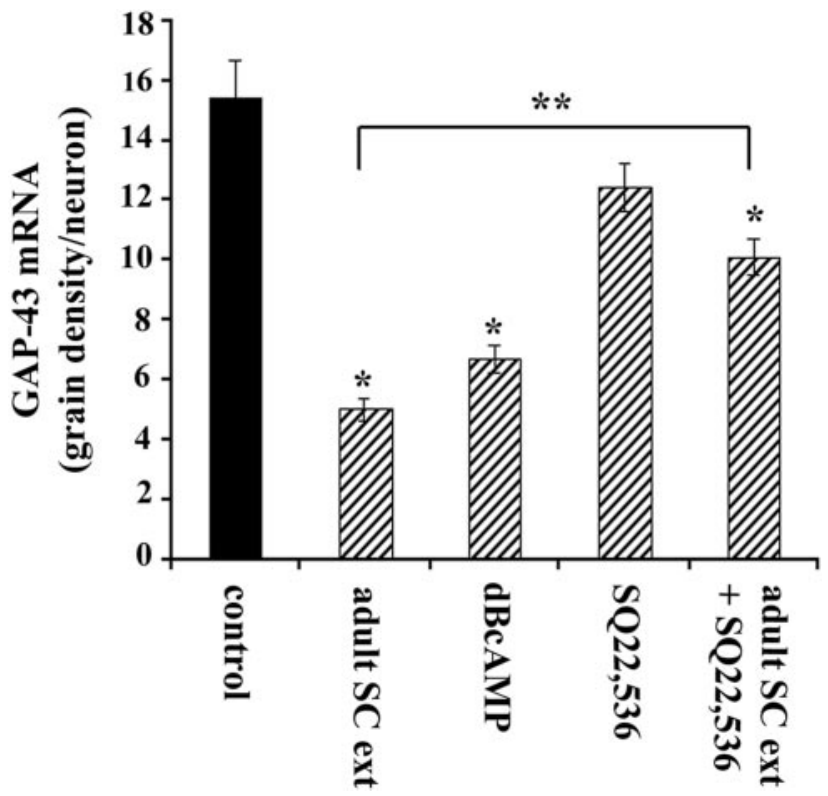

Figure 5. Activation of the cAMP signaling represses GAP-43 expression in cultured cerebral cortical neurons. Quantitative in situ hybridization for GAP-43 in cultures prepared from P8 cortex showed that exposure to either adult spinal cord extract or $0.5 \mathrm{~mm}$ dBcAMP caused a significant reduction in GAP-43 mRNA compared with control cultures after $6 \mathrm{~d}$ in culture ${ }^{*} p<0.001$; one-way ANOVA followed by Tukey's test). Exposure to $0.2 \mathrm{~mm}$ adenyl cyclase inhibitor SQ22,536 alone caused a small apparent reduction in GAP-43 expression, but this was not significant ( $p>0.05$; Tukey's test). Cultures treated with both spinal cord extract and SQ22,536 showed a significantly greater level of GAP-43 expression than cultures treated with spinal cord extract alone $\left({ }^{* *} p<\right.$ 0.001; Tukey's test). Error bars indicate SEM.

sparsely branched when they invade the gray matter during the first two postnatal weeks, but they gradually become more tortuous and highly branched, and exhibit increasing numbers of varicosities, until they achieve their adult appearance at $\sim \mathrm{P} 28$ (Karimi-Abdolrezaee, Verge, and Schreyer, unpublished observations).

It has been proposed that developmental downregulation of GAP-43 may be caused by either a reduction of positive factors or a production of inhibitory factors in the maturing CNS environment (Kalil and Skene, 1986). Normal downregulation of GAP-43 mRNA occurs in two phases during the postnatal period. The first occurs between P8 and P12, corresponding to the period of axon loss, and initial target invasion. The second occurs between P21 and P28, corresponding to the appearance of large numbers of varicosities and attainment of final form. Between these declines, GAP-43 expression is remarkably stable at an intermediate level (Karimi-Abdolrezaee, Verge, and Schreyer, unpublished observations).

Some observations have suggested that contact with CNS myelin causes GAP-43 repression in CNS neurons (Kapfhammer and Schwab, 1994a,b; Zagrebelsky et al., 1998), and our spinal cord extracts may have contained protein derived from myelin. However, our previous work shows that there is no temporal correlation between myelination and downregulation of GAP-43 immunoreactivity during development of ascending DRG and descending CST axons in the rat spinal cord. Furthermore, we found that contact with CNS myelin, although it could inhibit growth, had no effect on GAP-43 expression in cultures of central or peripheral neurons. In particular, exposure to CNS myelin failed to repress GAP-43 expression in cultures prepared from embryonic cortex, or in P8 cortical cultures similar to those used in the present study (S. Karimi-Abdolrezaee, P. Andersen, and D. Schreyer, unpublished observations).

Based in part on these findings, we now examine an alternative hypothesis that GAP-43 expression may be influenced by targetderived repressive factors. The two phases of GAP-43 mRNA decline in CST neurons appear to correspond with two aspects of target contact; initial target invasion and achievement of the mature pattern of synaptic contact. We designed our experiments to focus on the final, rather than the initial phase of GAP-43 mRNA decline. In motor neurons, it is the final process of synaptic reorganization, occurring long after initial target contact, which seems to be important for GAP-43 downregulation (Caroni and Becker, 1992).

\section{Retrograde regulation of GAP-43 in CST neurons}

We show that blockade of axonal transport with colchicine prevents the second phase of developmental downregulation of GAP-43 mRNA in CST neurons normally occurring between P21 and P28. Although colchicine may have unintended side effects, we demonstrated that our colchicine treatment did block retrograde axonal transport, and therefore would have prevented CST neurons from receiving any retrograde signals from their axon terminals during the period of application. If colchicine had blocked the transport of a positive regulatory signal that cortical neurons receive from their environment, we would have expected to see a decrease, rather than an increase in GAP-43 mRNA expression.

In further support of the concept of retrograde repression, we showed that extracts prepared from spinal cord target tissue, but not other tissues, could cause a premature downregulation of GAP-43 mRNA expression in CST neurons. This occurred when target extract was inf used over the period from P13 to P18, a time when GAP-43 mRNA levels are normally stable (KarimiAbdolrezaee, Verge, and Schreyer, unpublished observations). Spinal cord extract could also downregulate GAP-43 mRNA in cultures prepared from cortical neurons at P8. The spinal cord repressive activity could be captured in extracts of spinal cord tissue as young as P8. Thus, both the production of repressive activity in spinal cord, and the sensitivity to it by cortical neurons, occur well before the final downregulation of GAP-43 mRNA normally occurs in vivo. This would suggest that access to preexisting spinal cord repressive factor, perhaps as a part of synaptic maturation, is the crucial factor in triggering the final mature pattern of low GAP-43 mRNA expression in CST neurons.

In contrast to our in vivo studies, repression of GAP-43 mRNA expression was observed in cortical cultures after exposure to extracts from cerebellum. Because cerebellum is not a normal target of CST neurons, this finding suggests that a portion of the repression observed in vitro may be caused by nonspecific factors. It should be noted that in our cortical cultures we were not able to separate or identify CST neurons from other cortical neurons. Thus, we cannot be certain in these experiments whether particular subpopulations of cortical neurons were differentially effected by spinal cord versus cerebellar extracts.

\section{The effects of cAMP on GAP-43 mRNA}

Our findings that activation of the cAMP signaling pathway induces GAP-43 repression in cultured postnatal cortical neurons correlates with the previous findings that cAMP decreases GAP-43 expression in Schwann cells (Scherer et al., 1994; Stewart 
et al., 1995), DRG neurons (Andersen et al., 2000a), and RN46A cells (Andersen et al., 2000b). This intracellular GAP-43 repressive pathway therefore appears to be shared by several different nervous system cell types.

Because cAMP production usually occurs downstream of a G-protein-linked cell surface receptor, we studied whether cAMP could mediate the repressive effects of target-derived factors acting extracellularly. We found that inhibition of adenyl cyclase blocked the ability of spinal cord extract to repress GAP-43 expression in P8 cortical cultures, at least partially. This partial inhibition suggests that either the concentration of SQ22,536 we used was not enough to reverse all of the effects of the spinal cord extract, or that the repressive activity of the target extract is also partially mediated by other intracellular pathways.

Previous work suggests that the final decline of GAP-43 expression as CST neurons mature correlates not with initial target contact, but with maturation of terminal arbor morphology. We now show that the normal final decline of GAP-43 mRNA expression can be prevented by interrupting retrograde axonal transport at the appropriate time, or can be induced prematurely by infusing soluble extracts from target tissue. Repressive activity and the ability to respond to it appear to be in place before GAP-43 downregulation normally occurs in vivo, indicating that access to repressive activity may be an important issue in understanding developmental downregulation of GAP-43. The action of target extract on GAP-43 mRNA expression in cortical neurons may be mediated, at least in part, by cAMP signaling.

\section{REFERENCES}

Andersen PL, Webber CA, Kimura KA, Schreyer DJ (2000a) Cyclic AMP prevents an increase in GAP-43 but promotes neurite growth in cultured adult rat dorsal root ganglion neurons. Exp Neurol 166:153-165.

Andersen PL, Webber CA, Whittemore SR, Schreyer DJ (2000b) Divergent regulation of GAP-43 expression and CNS neurite outgrowth by cyclic AMP. J Neurosci Res 61:626-635.

Baizer L, Fishman MC (1987) Recognition of specific targets by cultured dorsal root ganglion neurons. J Neurosci 7:2305-2311.

Basi GS, Jacobson RD, Virag I, Schilling J, Skene JH (1987) Primary structure and transcriptional regulation of GAP-43, a protein associated with nerve growth. Cell 49:785-791.

Benowitz LI, Lewis ER (1983) Increased transport of 44,000- to 49,000dalton acidic proteins during regeneration of the goldfish optic nerve: a two-dimensional gel analysis. J Neurosci 3:2153-2163.

Benowitz LI, Routtenberg A (1997) GAP-43: an intrinsic determinant of neuronal development and plasticity. Trends Neurosci 20:84-91.

Berry M, Rogers AW (1965) The migration of neuroblasts in the developing cerebral cortex. J Anat 99:691-709.

Bisby MA (1988) Dependence of GAP43 (B50, F1) transport on axonal regeneration in rat dorsal root ganglion neurons. Brain Res 458:157-161.

Bormann P, Zumsteg VM, Roth LW, Reinhard E (1998) Target contact regulates GAP-43 and alpha-tubulin mRNA levels in regenerating retinal ganglion cells. J Neurosci Res 52:405-419.

Campbell G, Anderson PN, Turmaine M, Lieberman AR (1991) GAP-43 in the axons of mammalian CNS neurons regenerating into peripheral nerve grafts. Exp Brain Res 87:67-74.

Caroni P, Becker M (1992) The downregulation of growth-associated proteins in motoneurons at the onset of synapse elimination is controlled by muscle activity and IGF1. J Neurosci 12:3849-3861.

Dani JW, Armstrong DM, Benowitz LI (1991) Mapping the development of the rat brain by GAP-43 immunocytochemistry. Neuroscience 40:277-287.

Donatelle JM (1977) Growth of the corticospinal tract and the development of placing reactions in the postnatal rat. J Comp Neurol 175:207-231.

Fitzgerald M, Reynolds ML, Benowitz LI (1991) GAP-43 expression in the developing rat lumbar spinal cord. Neuroscience 41:187-199.

Giehl KM, Tetzlaff W (1996) BDNF and NT-3, but not NGF, prevent axotomy-induced death of rat corticospinal neurons in vivo. Eur J Neurosci 8:1167-1175.

Gribnau AA, de Kort EJ, Dederen PJ, Nieuwenhuys R (1986) On the development of the pyramidal tract in the rat. II. An anterograde tracer study of the outgrowth of the corticospinal fibers. Anat Embryol 175:101-110.

Hicks SP, D'Amato CJ (1968) Cell migrations to the isocortex in the rat. Anat Rec 160:619-634.

Houenou LJ, McManaman JL, Prevette D, Oppenheim RW (1991) Regulation of putative muscle-derived neurotrophic factors by muscle activity and innervation: in vivo and in vitro studies. J Neurosci 11:2829-2837.

Jacobson RD, Virag I, Skene JH (1986) A protein associated with axon growth, GAP-43, is widely distributed and developmentally regulated in rat CNS. J Neurosci 6:1843-1855.

Kalil K, Skene JH (1986) Elevated synthesis of an axonally transported protein correlates with axon outgrowth in normal and injured pyramidal tracts. J Neurosci 6:2563-2570.

Kapfhammer JP, Schwab ME (1994a) Increased expression of the growth-associated protein GAP-43 in the myelin-free rat spinal cord. Eur J Neurosci 6:403-411.

Kapfhammer JP, Schwab ME (1994b) Inverse patterns of myelination and GAP-43 expression in the adult CNS: neurite growth inhibitors as regulators of neuronal plasticity? J Comp Neurol 340:194-206.

Miller MW (1987a) Effect of prenatal exposure to alcohol on the distribution and time of origin of corticospinal neurons in the rat. J Comp Neurol 257:372-382.

Miller MW (1987b) The origin of corticospinal projection neurons in rat. Exp Brain Res 67:339-351.

Oudega M, Varon S, Hagg T (1994) Distribution of corticospinal motor neurons in the postnatal rat: quantitative evidence for massive collateral elimination and modest cell death. J Comp Neurol 347:115-126.

Scherer SS, Xu YT, Roling D, Wrabetz L, Feltri ML, Kamholz J (1994) Expression of growth-associated protein- $43 \mathrm{kD}$ in Schwann cells is regulated by axon-Schwann cell interactions and cAMP. J Neurosci Res 38:575-589.

Schreyer DJ, Jones EG (1982) Growth and target finding by axons of the corticospinal tract in prenatal and postnatal rats. Neuroscience 7:1837-1853.

Schreyer DJ, Jones EG (1988) Axon elimination in the developing corticospinal tract of the rat Brain Res [Erratum (1988) 467:320] 466:103-119.

Schreyer DJ, Skene JH (1991) Fate of GAP-43 in ascending spinal axons of DRG neurons after peripheral nerve injury: delayed accumulation and correlation with regenerative potential. J Neurosci 11:3738-3751.

Schreyer DJ, Andersen PL, Williams K, Kosatka I, Truong TN (1997) Quantitative analysis of GAP-43 expression by neurons in microcultures using cell-ELISA. J Neurosci Methods 72:137-145.

Skene JH (1989) Axonal growth-associated proteins. Annu Rev Neurosci 12:127-156.

Skene JH, Willard M (1981) Axonally transported proteins associated with axon growth in rabbit central and peripheral nervous systems. J Cell Biol 89:96-103.

Stanfield BB, O'Leary DD (1985) The transient corticospinal projection from the occipital cortex during the postnatal development of the rat. J Comp Neurol 238:236-248.

Stewart HJ, Curtis R, Jessen KR, Mirsky R (1995) TGF-beta s and cAMP regulate GAP-43 expression in Schwann cells and reveal the association of this protein with the trans-Golgi network. Eur J Neurosci 7:1761-1772.

Strittmatter SM, Vartanian T, Fishman MC (1992) GAP-43 as a plasticity protein in neuronal form and repair. J Neurobiol 23:507-520.

Verge VM, Merlio JP, Grondin J, Ernfors P, Persson H, Riopelle RJ, Hokfelt T, Richardson PM (1992) Colocalization of NGF binding sites, trk mRNA, and low-affinity NGF receptor mRNA in primary sensory neurons: responses to injury and infusion of NGF. J Neurosci 12:4011-4022.

Woolf CJ, Reynolds ML, Molander C, O'Brien C, Lindsay RM, Benowitz LI (1990) The growth-associated protein GAP-43 appears in dorsal root ganglion cells and in the dorsal horn of the rat spinal cord following peripheral nerve injury. Neuroscience 34:465-478.

Yamawaki M, Zurbriggen A, Richard A, Vandevelde M (1993) Saponin treatment for in situ hybridization maintains good morphological preservation. J Histochem Cytochem 41:105-109.

Zagrebelsky M, Buffo A, Skerra A, Schwab ME, Strata P, Rossi F (1998) Retrograde regulation of growth-associated gene expression in adult rat Purkinje cells by myelin-associated neurite growth inhibitory proteins. J Neurosci 18:7912-7929. 